\title{
Vegetarianism and other eating practices among youth and young adults in major Canadian cities
}

\author{
Laura Vergeer $^{1} \odot$, Lana Vanderlee ${ }^{1,2}$, Christine M White ${ }^{2}$, Vicki L Rynard ${ }^{2}$ and \\ David Hammond ${ }^{2, *}$ \\ 'Department of Nutritional Sciences, Faculty of Medicine, University of Toronto, Toronto, Ontario, Canada: ${ }^{2}$ School of \\ Public Health and Health Systems, University of Waterloo, Waterloo, Ontario, Canada, N2L 3G1
}

Submitted 4 March 2019: Final revision received 29 May 2019: Accepted 26 June 2019: First published online 11 October 2019

\begin{abstract}
Objective: To estimate the prevalence and sociodemographic characteristics of youth and young adults in major Canadian cities with self-reported vegetarian dietary practices and examine efforts to alter their diets.

Design: Data were collected in autumn 2016 via web-based surveys. Respondents reported vegetarian dietary practices (vegan, vegetarian or pescatarian) and efforts in the preceding year to consume more or less of several nutrients, food groups and/or foods with particular attributes. Logistic regression models examined sociodemographic correlates of each vegetarian dietary practice and differences in other eating practices by diet type.

Setting: Participants were recruited from five major Canadian cities.

Participants: Youth and young adults, aged $16-30$ years ( $n$ 2566).

Results: Overall, $13.6 \%$ of respondents reported vegetarian dietary practices: $6.6 \%$ vegetarian, $4.5 \%$ pescatarian and $2.5 \%$ vegan. Sex, race/ethnicity, selfreported frequency of using the Nutrition Facts table and health literacy were significantly correlated with self-reported vegetarian dietary practice $(P<0.01$ for all). Efforts to consume more fruits and vegetables $(66.8 \%)$ and protein $(54.8 \%)$, and less sugar $(61.3 \%)$ and processed foods $(54.7 \%)$, were prevalent overall. Respondents with vegetarian dietary practices were more likely to report efforts to consume fewer carbohydrates and animal products, and more organic, locally produced, ethically sourced/sustainably sourced/fair trade and non-GM foods $(P<0.01$ for all $)$, compared with those without these reported dietary practices.

Conclusions: Nearly $14 \%$ of the sampled youth and young adults in major Canadian cities reported vegetarian dietary practices and may be especially likely to value and engage in behaviours related to health-conscious diets and sustainable food production.
\end{abstract}

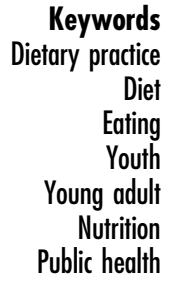

Poor diet quality is a major risk factor for obesity and noncommunicable diseases, which have become increasingly prevalent in Canada over the past few decades ${ }^{(1)}$. Many Canadians have low intakes of fruits and vegetables, whole grains and plant-based proteins such as legumes, nuts and seeds ${ }^{(2-5)}$. In addition, approximately half of Canadians' daily energy intake is derived from foods that are heavily processed, which are typically high in kilojoules, saturated fat, sodium and sugars ${ }^{(6)}$. Diet quality is particularly poor among Canadian youth and young adults. Compared with older adults in Canada, those aged 19-30 years have been shown to obtain a greater proportion of their daily energy intake from foods not recommended in Eating Well with Canada's Food Guide ${ }^{(7)}$. Similarly, consumption of ultra-processed foods is higher among younger adults in Canada than in those aged 35 years or above ${ }^{(6)}$.

Research has also demonstrated that eating behaviours developed during the transition from adolescence to adulthood often persist into later life ${ }^{(8)}$. It is therefore important to establish healthy dietary practices among youth and young adults ${ }^{(9)}$.

While the importance of healthy eating is well established, less is known about how Canadians are making efforts to improve the quality of their diet. An online survey 
of 5494 Canadians adults aged 20-69 years indicated that nearly $65 \%$ of Canadians had attempted to improve their eating habits within the preceding 2 months ${ }^{(10)}$. The authors also noted that of the respondents who did not express concern about the quality of their diet ( $40 \%$ of the total sample), $40 \%$ had still made an effort to alter their eating habits. These findings are in agreement with those of 2017 market research surveys which indicated that most Canadians (76\%) have been making efforts to make healthy food choices all or most of the time; $51 \%$ of Canadian consumers claimed to be eating healthier than they have in the past and $59 \%$ reported actively purchasing healthier foods ${ }^{(11,12)}$.

One potential way to improve diet quality is to consume plant-based protein foods more often than animal-based alternatives $^{(5)}$. Diets that emphasize plant-based foods typically give rise to higher intakes of dietary fibre, fruit and vegetables, nuts and soya protein, which have been associated with reduced risk of developing high LDL-cholesterol, CVD, colon cancer and/or type 2 diabetes $^{(5,13,14)}$. These eating patterns also have potential environmental benefits, such as reduced use of energy, water and soil in food production, which is among the greatest contributors to worldwide environmental degradation $^{(15)}$. A global transformation to more plantbased and sustainable diets has been recommended by the UN and others as a means of helping to achieve the Sustainable Development Goals and the Paris Agreement on climate change ${ }^{(15,16)}$. The importance of diets that are both healthy and environmentally sustainable is also reflected in Canada's recently updated Food Guide, which emphasizes shifting intakes towards more plant-based foods and, when consuming animal-based foods, choosing those lower in saturated fat and sodium (e.g. lean red meat, lower-fat milk and yoghurt, cheeses containing less fat and sodium $)^{(5)}$. By definition, vegetarian dietary practices exclude meat, but may include seafood (pescatarian), dairy and/or egg products (ovo-vegetarian, lacto-vegetarian or ovo-lacto-vegetarian; hereafter referred to as 'vegetarian'), or no animal products or by-products (vegan) ${ }^{(17)}$.

While many Canadians report that they are interested in improving the healthfulness of their diets ${ }^{(10-12)}$, few studies have examined what efforts are being made by Canadians to consume more or less of several nutrients, food groups or foods with particular attributes (e.g. processed, organic, locally sourced) in order to achieve this goal. Additionally, little research has examined the prevalence of vegetarian dietary practices and the sociodemographic characteristics associated with these diets in Canadians, particularly among youth and young adults. The objectives of the present study were to: (i) estimate the prevalence of self-reported vegetarian dietary practices among youth and young adults in major Canadian cities, and explore sociodemographic correlates of these dietary practices; (ii) determine whether Canadian youth and young adults report having made efforts to consume more or less of several nutrients and food components, food groups and food attributes ('eating practices'); and (iii) examine whether these reported eating practices differed between Canadian youth and young adults with and without vegetarian dietary practices.

\section{Methods}

\section{Procedure}

Data were collected via self-completed web-based surveys between October and December of 2016 as part of the Canada Food Study. Respondents were recruited from five Canadian cities: Vancouver (BC), Edmonton $(\mathrm{AB})$, Toronto (ON), Montreal (QC) and Halifax (NS). Participants were recruited using in-person intercept recruitment from selected sites in each city, using a stratified sample of sites. For each city, a sampling frame of shopping centres and public areas was constructed, stratified by region/neighbourhood and type of site (mall, transit hub, park, or other shopping district). Individuals were screened during recruitment for study eligibility; they were considered eligible if they resided in one of the five cities, were 16-30 years of age, had access to the Internet as well as a laptop, desktop computer or tablet, and had not previously enrolled in the study panel. Eligible individuals who provided their email address were sent a personalized link to complete the online survey in English or French. Respondents were discouraged from accessing the surveys via smartphone, but were not restricted from doing so.

Respondents received a CAN\$2 cash incentive upon initial recruitment and a CAN\$ 20 Interac e-transfer after completing the study. Respondents provided consent electronically prior to completing the survey. A full description of the study methods can be found in the Technical Report $^{(18)}$.

\section{Measures}

\section{Vegetarian dietary practices}

Respondents were asked to indicate whether they had any vegetarian and/or religious dietary practices by selecting one or more of the following options: 'vegetarian'; 'vegan'; 'pescatarian'; 'following a religious practice for eating'; 'none of the above'; 'don't know'; or 'refuse to answer'.

\section{Other eating practices}

Respondents were asked whether they had made an effort to consume more or less of the following in the past year (by selecting 'consume less', 'consume more', 'no effort made', 'don't know' or 'refuse to answer'): calories; carbohydrates; fat; trans fat; protein; fibre; sugar/added sugar; salt/sodium; cholesterol; vitamin D; fruits and vegetables; whole grains; dairy products; all meats; red meat (e.g. beef, pork) only; gluten; aspartame; other 
low-calorie sweeteners; processed foods; genetically modified organisms (GMO); organic foods; locally produced foods; ethnically sourced, sustainably sourced or fair trade foods; or other (specified by respondent). These variables were organized into three categories: (i) nutrients or food components (e.g. calories, fat, sugar, vitamin D); (ii) food groups (e.g. fruits and vegetables, whole grains, dairy products, meats); and (iii) food attributes (e.g. gluten, aspartame, processed, organic, ethically sourced/sustainably sourced/fair trade foods).

\section{Sociodemographic characteristics}

The survey collected information about respondents' sociodemographic variables, including age, sex at birth (male or female), city of recruitment (Vancouver, Edmonton, Toronto, Montreal or Halifax), race/ethnicity, BMI, education level and perceived income adequacy. Race/ethnicity was determined through a measure that asked respondents to identify which racial or ethnic group(s) applied to them. The responses were collapsed into six categories ('only' denotes identification with a single racial/ethnic group): 'White only'; 'South Asian only'; 'Black only'; 'Chinese only'; 'Aboriginal (including mixed)'; and 'mixed/other/not stated/missing' which included those who selected Filipino, Latin, Southeast Asian, Arab, West Asian, Japanese, Korean, other, or more than one racial or ethnic group (except Aboriginal), or those who did not respond. BMI was calculated using self-reported height and weight, and categorized as 'underweight' $\left(<18.5 \mathrm{~kg} / \mathrm{m}^{2}\right)$, 'normal weight' $\left(18.5-24.9 \mathrm{~kg} / \mathrm{m}^{2}\right)$, 'overweight' $\left(25 \cdot 0-29 \cdot 9 \mathrm{~kg} / \mathrm{m}^{2}\right)$, 'obese' $\left(\geq 30 \mathrm{~kg} / \mathrm{m}^{2}\right)$ or 'not stated'. For educational attainment, respondents were grouped into one of the following categories: 'high school or less'; 'CEGEP/trade school/college (partial or complete)'; 'university (partial or complete)'; or 'not stated/missing'. To assess perceived income adequacy, respondents were asked how difficult or easy it is to make ends meet based on their total monthly income ('very difficult'; 'difficult'; 'neither easy nor difficult'; 'easy'; 'very easy'; 'don't know'; or 'refuse to answer'); respondents who selected 'don't know' or 'refuse to answer' were grouped into a 'not stated/missing' category.

\section{Health literacy, nutrition knowledge and Nutrition Facts table use}

The Newest Vital Sign (NVS; Pfizer, Inc.) measure was adapted for online administration in Canada and used as an objective measure of health literacy ${ }^{(19)}$. Based on NVS scores, respondents were categorized as having: a 'high likelihood of limited literacy' (score $=0$ or 1); a 'possibility of limited literacy' (score $=2$ or 3); or 'adequate literacy' (score $=4-6$ ). Respondents rated their nutrition knowledge by selecting: 'not at all knowledgeable'; 'a little knowledgeable'; 'somewhat knowledgeable'; 'very knowledgeable'; 'extremely knowledgeable'; 'don't know'; or 'refuse to answer'. Respondents were also asked how often they use the Nutrition Facts table (NFt) when deciding to buy a food product ('never'; 'rarely'; 'sometimes'; 'most of the time'; 'always'; 'don't know'; or 'refuse to answer').

\section{Data analysis}

Post-stratification sample weights were constructed based on 2016 population estimates from Statistics Canada's postcensal CANSIM tables ${ }^{(20)}$. For each age by sex group, weights were calculated as the population proportion divided by the sample proportion, ensuring the weighted sample aligns with known population proportions. Weights were applied to the full data set of 3000 respondents. Estimates reported are weighted unless otherwise specified. The final analytic sample ( $n$ 2566) excluded respondents with missing data for the vegetarian dietary practices and other eating practices variables as well as those who selected more than one vegetarian or religious dietary practice response option or selected 'refuse to answer'. Respondents who selected 'don't know' or reported religious dietary practices were recoded into the 'none of the above [vegetarian dietary practices]' category.

Logistic regression models investigated sociodemographic correlates of each type of vegetarian dietary practice. Adherence to each vegetarian dietary practice (i.e. vegan, vegetarian or pescatarian) $v$. all other diet types (including reporting none of these dietary practices) was examined as a binary dependent variable. Covariates included age (continuous), sex at birth, city of recruitment, race/ethnicity, BMI classification, education level, self-reported income adequacy, health literacy, self-reported nutrition knowledge, frequency of NFt use, and whether the survey was completed on a smartphone $v$. a desktop computer, laptop or tablet. The following variables were recoded as follows to account for small numbers of observations in some categories when examined by vegetarian dietary practice: race/ethnicity ('White only'; 'South Asian only'; 'Black only or Chinese only or Aboriginal'; 'Mixed or other or not stated'); income adequacy ('very difficult or difficult'; 'neither easy nor difficult'; 'easy or very easy'; 'not stated'); nutrition knowledge ('a little or not at all knowledgeable'; 'somewhat knowledgeable'; 'very or extremely knowledgeable'); and frequency of NFt use ('never or rarely'; 'sometimes'; 'most of the time'; 'always'). All contrasts within categorical variables were tested. Respondents who did not specify their educational background, nutrition knowledge and/or NFt use were excluded from the regression analyses, resulting in a sample size in the models of $n 2402$.

Descriptive statistics were used to examine the proportion of respondents overall and according to type of vegetarian dietary practice (i.e. vegan, vegetarian, pescatarian, none of those) that reported having made an effort to shift towards a diet generally considered more healthful, health-conscious (or sometimes perceived to be healthier by the public), or otherwise often perceived more 
positively, for example, in terms of the environment. This included efforts to consume more protein, fibre, vitamin D, fruits and vegetables, whole grains, and foods that are organic, locally produced and/or ethically sourced/sustainably sourced/fair trade, and efforts to consume less calories, carbohydrates, fat, trans fat, sugar, sodium, cholesterol, aspartame and/or other low-calorie sweeteners, dairy products, all meats, red meat only, gluten, processed foods and/or GMO. Binary variables were created to compare respondents who reported the eating practice of interest (e.g. effort to consume more protein) against those who selected one of the following: the opposite eating practice (e.g. effort to consume less protein); 'no effort made'; 'don't know'; or 'refuse to answer'. Separate binary logistic regression models were constructed for each eating practice variable, adjusted for the sociodemographic characteristics described above and with type of vegetarian dietary practice as the covariate of interest. Chi-square tests derived from the models were used to identify significant differences in eating practices according to type of vegetarian dietary practice. To reduce the probability of Type I error, correlates of self-reported vegetarian dietary practices and differences in eating practices between diet types (vegan, vegetarian, pescatarian or none of these) were considered statistically significant only when $P<0 \cdot 01$. Analyses were conducted using the statistical software package IBM SPSS Statistics version 25.

\section{Results}

\section{Sample description}

Table 1 provides a description of the analytic sample ( $n$ 2566). Nearly half of the respondents were between the ages of 19 and 25 years (48.0\%), with an average weighted age of 23.3 years. Almost half of respondents identified as White only (48.0\%) and over a quarter identified as having mixed/other or unknown race/ethnicity (28.5\%). Overall, $59.2 \%$ of the sample had a university degree either completed or in progress, and about half reported their income adequacy as either very low or low $(22.6 \%)$, or high or very high $(27.9 \%)$.

Table 1 Analytic sample characteristics of the youth and young adults aged $16-30$ years in five major Canadian cities, Canada Food Study, 2016 (n2566)

\begin{tabular}{lccc}
\hline Characteristic & Unweighted \% & $n$ & Weighted \% \\
\hline Age group (years) & & & \\
$16-18$ & 23.9 & 612 & $16 \cdot 7$ \\
$19-21$ & $29 \cdot 3$ & 753 & 19.7 \\
$22-25$ & 27.6 & 708 & $28 \cdot 3$ \\
$26-30$ & $19 \cdot 2$ & 493 & $35 \cdot 3$ \\
\hline
\end{tabular}

Table 1 Continued

\begin{tabular}{|c|c|c|c|}
\hline Characteristic & Unweighted \% & $n$ & Weighted \% \\
\hline \multicolumn{4}{|l|}{ Sex at birth } \\
\hline Male & 38.0 & 976 & 49.9 \\
\hline Female & $62 \cdot 0$ & 1590 & $50 \cdot 1$ \\
\hline \multicolumn{4}{|l|}{ City of recruitment } \\
\hline Edmonton & $17 \cdot 4$ & 446 & $16 \cdot 5$ \\
\hline Halifax & $20 \cdot 0$ & 513 & $18 \cdot 1$ \\
\hline Montreal & $18 \cdot 4$ & 473 & 19.5 \\
\hline Toronto & $25 \cdot 1$ & 644 & $24 \cdot 1$ \\
\hline Vancouver & $19 \cdot 1$ & 490 & 21.9 \\
\hline \multicolumn{4}{|l|}{ Race/ethnicity } \\
\hline White only & $47 \cdot 1$ & 1209 & $48 \cdot 0$ \\
\hline Chinese only & 8.6 & 220 & 8.4 \\
\hline South Asian only & $6 \cdot 0$ & 155 & $6 \cdot 2$ \\
\hline Black only & $5 \cdot 3$ & 136 & $5 \cdot 1$ \\
\hline Aboriginal (including mixed) & $4 \cdot 1$ & 104 & 3.9 \\
\hline $\begin{array}{l}\text { Mixed or other, not stated } \\
\text { or missing }\end{array}$ & 28.9 & 742 & $28 \cdot 5$ \\
\hline \multicolumn{4}{|l|}{ BMI classification } \\
\hline Underweight & $7 \cdot 2$ & 185 & $6 \cdot 1$ \\
\hline Normal weight & 52.4 & 1345 & 52.4 \\
\hline Overweight & $16 \cdot 6$ & 425 & $18 \cdot 1$ \\
\hline Obese & 8.0 & 205 & $8 \cdot 3$ \\
\hline Not stated or missing & $15 \cdot 8$ & 406 & $15 \cdot 1$ \\
\hline \multicolumn{4}{|l|}{ Education completed } \\
\hline High school or less & $18 \cdot 4$ & 473 & $17 \cdot 1$ \\
\hline $\begin{array}{l}\text { CEGEP/trade school/college } \\
\text { (partial or complete) }\end{array}$ & $22 \cdot 1$ & 567 & 21.8 \\
\hline $\begin{array}{l}\text { University } \\
\text { (partial or complete) }\end{array}$ & $57 \cdot 8$ & 1484 & $59 \cdot 2$ \\
\hline Not stated or missing & 1.6 & 42 & 1.9 \\
\hline \multicolumn{4}{|l|}{ Perceived income adequacy } \\
\hline Very low & $5 \cdot 3$ & 137 & 5.5 \\
\hline Low & $16 \cdot 5$ & 423 & $17 \cdot 1$ \\
\hline Neither low nor high & $37 \cdot 0$ & 950 & 37.5 \\
\hline High & 17.4 & 446 & $17 \cdot 8$ \\
\hline Very high & $10 \cdot 0$ & 257 & $10 \cdot 1$ \\
\hline Not stated or missing & 13.8 & 353 & $12 \cdot 0$ \\
\hline \multicolumn{4}{|l|}{ Self-rated nutrition knowledge } \\
\hline Not at all knowledgeable & $5 \cdot 1$ & 132 & $4 \cdot 8$ \\
\hline A little knowledgeable & 29.9 & 767 & 28.5 \\
\hline Somewhat knowledgeable & $46 \cdot 0$ & 1180 & $46 \cdot 7$ \\
\hline Very knowledgeable & $15 \cdot 7$ & 402 & $16 \cdot 2$ \\
\hline Extremely knowledgeable & 1.9 & 50 & $2 \cdot 3$ \\
\hline Not known or reported & 1.4 & 35 & 1.4 \\
\hline \multicolumn{4}{|l|}{ Literacy status } \\
\hline $\begin{array}{l}\text { High likelihood of limited } \\
\text { literacy }\end{array}$ & 11.5 & 294 & 11.5 \\
\hline Possibility of limited literacy & $20 \cdot 3$ & 522 & $18 \cdot 6$ \\
\hline Adequate literacy & 64.0 & 1643 & $65 \cdot 6$ \\
\hline Missing & 4.2 & 107 & 4.2 \\
\hline \multicolumn{4}{|c|}{ Frequency of Nutrition Facts table use } \\
\hline Never & 18.9 & 485 & $18 \cdot 2$ \\
\hline Rarely & $21 \cdot 0$ & 538 & 20.4 \\
\hline Sometimes & $30 \cdot 3$ & 777 & 30.5 \\
\hline Most of the time & $19 \cdot 8$ & 509 & 21.0 \\
\hline Always & $7 \cdot 8$ & 199 & 7.4 \\
\hline Not known or reported & $2 \cdot 3$ & 58 & 2.5 \\
\hline \multicolumn{4}{|l|}{ Veqetarian dietary practices } \\
\hline Vegan & $2 \cdot 8$ & 71 & 2.5 \\
\hline Vegetarian & $6 \cdot 7$ & 173 & $6 \cdot 6$ \\
\hline Pescatarian & 4.6 & 117 & 4.5 \\
\hline None of the above & 85.9 & 2205 & $86 \cdot 4$ \\
\hline \multicolumn{4}{|c|}{ Survey completion on mobile browser } \\
\hline $\begin{array}{l}\text { No indication of mobile } \\
\text { browser use }\end{array}$ & 86.0 & 2206 & $87 \cdot 0$ \\
\hline $\begin{array}{l}\text { Probable mobile } \\
\text { browser use }\end{array}$ & $14 \cdot 0$ & 360 & $13 \cdot 0$ \\
\hline
\end{tabular}




\section{Prevalence of vegetarian dietary practices}

Overall, $13.6 \%$ of respondents reported vegetarian dietary practices. As shown in Table 1, 6.6\% identified as vegetarian, $4.5 \%$ as pescatarian and $2.5 \%$ as vegan.

\section{Characteristics of respondents by type of vegetarian dietary practice}

Statistically significant correlates identified in the logistic regression analyses for each type of vegetarian dietary practice are described in the following subsections. Age, city of recruitment, BMI, perceived income adequacy, education, self-reported nutrition knowledge and probable survey completion on a mobile browser were not significantly associated with any of the types of vegetarian dietary practices. Adjusted OR estimates for comparisons between categories of all statistically significant correlates are reported in Table 2 .

\section{Vegan}

Frequency of using the NFt when deciding to buy a food product was a correlate of following a vegan diet $\left(\chi_{(4)}^{2}=31.50 ; \quad P<0.001\right)$. Respondents who reported always using the NFt were more likely to be vegan than those who reported using the NFt rarely or never (OR $=8.42 ; 95 \%$ CI 3.61, 19.65; $P<0.001)$, sometimes (OR $=4.27 ; 95 \%$ CI 2.09, 8.74; $P=0.001$ ) or most of the time $(\mathrm{OR}=6 \cdot 22 ; 95 \% \mathrm{CI} 2 \cdot 74,14 \cdot 14 ; P<0.001)$.

\section{Vegetarian}

Race/ethnicity was associated with following a vegetarian $\operatorname{diet}\left(\chi_{(3)}^{2}=63.12 ; P<0.001\right)$. South Asian only respondents were more likely to have a vegetarian diet than those who identified as White only (OR $=4.56 ; 95 \%$ CI 2.74, 7.60; $P<0.001$ ), Black only/Chinese only/Aboriginal (including mixed) $(\mathrm{OR}=24.55 ; 95 \%$ CI 9.40, 64.13; $P<0.001)$, or of mixed/other or unknown race/ethnicity $(\mathrm{OR}=5.91 ; 95 \%$ CI 3.37, 10.37; $P<0.001)$. White respondents and those with mixed/other or unknown race/ethnicity were both more likely to be vegetarian than respondents who identified as Black only/Chinese only/Aboriginal (including mixed) $(\mathrm{OR}=5 \cdot 38 ; 95 \%$ CI 2.17, 13.35; $P<0.001$ and $\mathrm{OR}=4.16 ; 95 \%$ CI $1.62,10.65 ; P=0.003$, respectively). Frequency of NFt use when deciding to buy a food product was also correlated with having a vegetarian $\operatorname{diet}\left(\chi_{(3)}^{2}=19.98 ; \quad P<0.001\right)$. Respondents who reported always using the NFt were more likely to be vegetarian than those who stated that they use the $\mathrm{NFt}$ rarely or never (OR $=3.70 ; 95 \%$ CI 2.04, 6.73; $P<0.001)$ or sometimes ( $\mathrm{OR}=2.53$; $95 \%$ CI $1.44,4.45$; $P=0.001)$. Respondents who reported using the NFt most of the time were also more likely to be vegetarian than those who rarely or never used the NFt (OR $=2 \cdot 04 ; 95 \%$ CI $1.24,3 \cdot 35 ; P=0.005)$.

\section{Pescatarian}

Females were more likely to be pescatarian than males $(\mathrm{OR}=2.45 ; 95 \%$ CI 1.57, 3.81; $P<0.001)$. Additionally, health literacy was associated with following a pescatarian diet $\left(\chi_{(2)}^{2}=11.51 ; P=0.003\right)$. Respondents with a high likelihood of limited health literacy were more likely to be pescatarian than those with adequate health literacy (OR $=2.90 ; 95 \%$ CI $1.55,5.44 ; P=0.001)$.

\section{Other eating practices}

An overview of efforts to consume more or less of each nutrient or component, food group or food attribute is provided in Table 3, presented for the overall sample and according to the type of vegetarian dietary practice. In terms of eating practices concerning nutrients or food components, in the overall sample, reported efforts to consume less sugar (61.3\%) and more protein (54.8\%) were most prevalent; efforts to reduce cholesterol consumption were the least common (30.4\%). With regard to food groups, many respondents reported trying to consume more fruits and vegetables (66.8\%) and/or whole grains $(44.1 \%)$, while efforts to consume less meat (all types) were least common (20.3\%). The most commonly reported eating practices related to food attributes were efforts to consume less processed foods $(54.7 \%)$ and more locally produced foods (42.9\%); the least common eating practice reported was efforts to consume less gluten (18.0\%). A greater proportion of respondents with self-reported vegan, vegetarian and/or pescatarian diets reported having made efforts to reduce their consumption of carbohydrates, all meats, red meat, dairy and GMO, and consume more organic, locally produced and ethically sourced/sustainably sourced/fair trade foods, compared with respondents who did not report those dietary practices $(P<0.01$ for all).

\section{Discussion}

Nearly $14 \%$ of the Canadian youth and young adults in our sample reported following a vegetarian, pescatarian or vegan diet. These results are slightly higher than estimates from a 2018 survey of 1027 Canadian adults ${ }^{(21)}$, which found that $5.6 \%$ of respondents described their dietary choices as vegetarian $(3.3 \%)$, pescatarian ( $1.2 \%)$ or vegan ( $1 \cdot 1 \%)$. This may be a reflection of the fact that our sample consisted entirely of youth and young adults - who may be more likely to follow these eating trends ${ }^{(22,23)}-$ and was largely urban. The 2018 survey also found that $63 \%$ of vegans were under 38 years of age, suggesting that diets with fewer animal-based foods are more prevalent among younger Canadians ${ }^{(21)}$. In the present study, $20 \%$ of respondents reported having made efforts to consume less meat (all types) in the preceding year, and $29 \%$ reported trying to reduce their intake of red meat, which is similar to the proportion in the 2018 survey that indicated $32 \%$ of Canadians were considering reducing their meat intake in the next 6 months ${ }^{(21)}$. Overall, these 


\section{NS Public Health Nutrition}

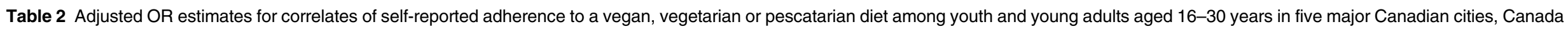
Food Study, 2016 (n2566)

\begin{tabular}{|c|c|c|c|c|c|c|c|c|c|}
\hline & \multicolumn{3}{|c|}{ Vegan } & \multicolumn{3}{|c|}{ Vegetarian } & \multicolumn{3}{|c|}{ Pescatarian } \\
\hline & $\chi^{2}, P$ value $^{*}$ & Adjusted OR & $95 \%$ Cl†,‡ & $\chi^{2}, P$ value $^{*}$ & Adjusted OR & $95 \%$ Cl†, $\ddagger$ & $\chi^{2}, P$ value $^{*}$ & Adjusted OR & $95 \%$ Cl†,‡ \\
\hline Age (years) & $0.12, P=0.73$ & & & $0.30, P=0.59$ & & & $0.14, P=0.71$ & & \\
\hline Sex & $0.14, P=0.71$ & & & $2 \cdot 81, P=0.09$ & & & $15.56, P<0.001$ & & \\
\hline Female $v$. male & & & & & & & & 2.45 & $1.57,3.81$ \\
\hline City of recruitment & $6.89, P=0.14$ & & & $8.64, P=0.07$ & & & 13.12, $P=0.01$ & & \\
\hline $\begin{array}{l}\text { Race/ethnicity } \\
\text { South Asian only } v \text {. White only }\end{array}$ & $9.26, P=0.03$ & & & $63.12, P<0.001$ & 4.56 & $2.74,7.60$ & $3.29, P=0.35$ & & \\
\hline $\begin{array}{l}\text { South Asian only v. Black/Chinese/ } \\
\text { Aboriginal }\end{array}$ & & & & & 24.55 & $9 \cdot 40,64 \cdot 13$ & & & \\
\hline $\begin{array}{l}\text { South Asian only v. Mixed/other/not } \\
\text { stated }\end{array}$ & & & & & $5 \cdot 91$ & $3.37,10.37$ & & & \\
\hline $\begin{array}{l}\text { White only } v \text {. Black/Chinese/ } \\
\text { Aboriginal }\end{array}$ & & & & & $5 \cdot 38$ & $2 \cdot 17,13 \cdot 35$ & & & \\
\hline $\begin{array}{l}\text { White only } v \text {. Mixed/other/not } \\
\text { stated }\end{array}$ & & & & & $1 \cdot 30$ & $0.82,2.04$ & & & \\
\hline $\begin{array}{l}\text { Mixed/other/not stated v. Black/ } \\
\text { Chinese/Aboriginal }\end{array}$ & & & & & $4 \cdot 16$ & $1.62,10.65$ & & & \\
\hline BMI classification & $7.00, P=0.14$ & & & $5.52, P=0.24$ & & & $2 \cdot 70, P=0.61$ & & \\
\hline Education completed & $2.59, P=0.27$ & & & $5 \cdot 17, P=0.08$ & & & $3.49, P=0.18$ & & \\
\hline Perceived income adequacy & $5.48, P=0.14$ & & & $0.51, P=0.92$ & & & $5 \cdot 00, P=0.17$ & & \\
\hline Health literacy & $3.90, P=0.14$ & & & $4.69, P=0.10$ & & & $11.51, P=0.003$ & & \\
\hline $\begin{array}{l}\text { High likelihood of limited literacy } v \text {. } \\
\text { possibility of limited literacy }\end{array}$ & & & & & & & & $1 \cdot 86$ & $0.93,3.70$ \\
\hline $\begin{array}{l}\text { High likelihood of limited literacy } v \text {. } \\
\text { adequate literacy }\end{array}$ & & & & & & & & 2.90 & $1 \cdot 55,5.44$ \\
\hline $\begin{array}{l}\text { Possibility of limited literacy } v \text {. } \\
\text { adequate literacy }\end{array}$ & & & & & & & & 1.56 & $0.92,2 \cdot 64$ \\
\hline Self-rated nutrition knowledge & $7.50, P=0.02$ & & & $3.84, P=0.15$ & & & $2 \cdot 10, P=0.35$ & & \\
\hline $\begin{array}{l}\text { Frequency of Nutrition Facts } \\
\text { table use }\end{array}$ & $31.50, P<0.001$ & & & $19.98, P<0.001$ & & & $5.60, P=0.13$ & & \\
\hline Always $v$. most of the time & & $6 \cdot 22$ & $2 \cdot 74,14.14$ & & $1 \cdot 81$ & $1.03,3.20$ & & & \\
\hline Always v. sometimes & & $4 \cdot 27$ & $2.09,8.74$ & & 2.53 & $1.44,4.45$ & & & \\
\hline Always $v$. rarely or never & & 8.42 & $3.61,19.65$ & & $\mathbf{3 . 7 0}$ & $2.04,6.73$ & & & \\
\hline Most of the time $v$. sometimes & & 0.69 & $0.31,1.52$ & & 1.40 & $0.88,2 \cdot 21$ & & & \\
\hline Most of the time $v$. rarely or never & & $1 \cdot 35$ & $0.55,3.32$ & & 2.04 & $1.24,3.35$ & & & \\
\hline Sometimes $v$. rarely or never & & 1.97 & $0.90,4.31$ & & 1.46 & $0.92,2.33$ & & & \\
\hline Survey completion on mobile browser & $0.33, P=0.57$ & & & & & & $0.03, P=0.86$ & & \\
\hline
\end{tabular}

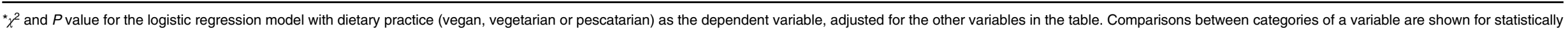

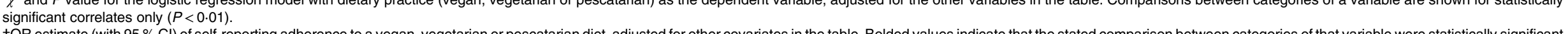

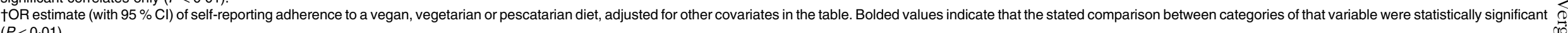

tReference category is listed second. 
Table 3 Reported eating practices of youth and young adults aged 16-30 years in five major Canadian cities in terms of recent efforts to consume more or less of certain nutrients and food components, food groups and/or food attributes, overall and by diet type*, Canada Food Study, 2016 (n2566)

\begin{tabular}{|c|c|c|c|c|c|c|c|c|c|c|c|}
\hline & \multicolumn{2}{|c|}{$\begin{array}{l}\text { Total sample } \\
\text { (n2558) }\end{array}$} & \multirow[b]{2}{*}{$\chi^{2}, P$ valuet } & \multicolumn{2}{|c|}{$\begin{array}{l}\text { Vegan } \\
(n 64)\end{array}$} & \multicolumn{2}{|c|}{$\begin{array}{l}\text { Vegetarian } \\
\quad(n 168)\end{array}$} & \multicolumn{2}{|c|}{$\begin{array}{l}\text { Pescatarian } \\
(n 114)\end{array}$} & \multicolumn{2}{|c|}{$\begin{array}{l}\text { None of the } \\
\text { above } \\
(n 2212)\end{array}$} \\
\hline & $\%$ & $n$ & & $\%$ & $n$ & $\%$ & $n$ & $\%$ & $n$ & $\%$ & $n$ \\
\hline \multicolumn{12}{|c|}{$\begin{array}{l}\text { Nutrients and food components } \\
\text { Protein }\end{array}$} \\
\hline $\begin{array}{l}\text { Consume more } \\
\text { Fibre }\end{array}$ & $54 \cdot 8$ & 1401 & $6 \cdot 84, P=0.08$ & $47 \cdot 7$ & 31 & $60 \cdot 7$ & 102 & $60 \cdot 5$ & 69 & $54 \cdot 2$ & 1199 \\
\hline $\begin{array}{l}\text { Consume more } \\
\text { Vitamin D }\end{array}$ & $48 \cdot 2$ & 1233 & $4.42, P=0.22$ & $48 \cdot 4$ & 31 & $47 \cdot 3$ & 80 & $51 \cdot 3$ & 59 & $48 \cdot 1$ & 1064 \\
\hline $\begin{array}{l}\text { Consume more } \\
\text { Calories }\end{array}$ & $35 \cdot 3$ & 904 & $1.42, P=0.70$ & 37.5 & 24 & $40 \cdot 5$ & 68 & $34 \cdot 8$ & 40 & 34.9 & 772 \\
\hline $\begin{array}{l}\text { Consume less } \\
\text { Carbohydrates }\end{array}$ & 38.4 & 982 & $0.27, P=0.97$ & $40 \cdot 0$ & 26 & 39.9 & 67 & $43 \cdot 9$ & 50 & $37 \cdot 9$ & 839 \\
\hline $\begin{array}{l}\text { Consume less } \\
\text { Fat }\end{array}$ & $35 \cdot 0$ & 895 & $12.70, P=0.005$ & $29 \cdot 7^{a, b}$ & 19 & $27 \cdot 4^{a}$ & 46 & $40 \cdot 0^{a, b}$ & 46 & $35 \cdot 4^{b}$ & 783 \\
\hline $\begin{array}{l}\text { Consume less } \\
\text { Trans fat }\end{array}$ & $40 \cdot 2$ & 1028 & $2.39, P=0.50$ & 39.1 & 25 & $44 \cdot 0$ & 74 & $50 \cdot 0$ & 57 & 39.4 & 872 \\
\hline $\begin{array}{l}\text { Consume less } \\
\text { Sugar/added sugar }\end{array}$ & $47 \cdot 6$ & 1217 & $4.48, P=0.21$ & $44 \cdot 6$ & 29 & $46 \cdot 7$ & 79 & $58 \cdot 8$ & 67 & $47 \cdot 1$ & 1042 \\
\hline $\begin{array}{l}\text { Consume less } \\
\text { Salt/sodium }\end{array}$ & $61 \cdot 3$ & 1568 & $1.93, P=0.59$ & 61.5 & 40 & 58.9 & 99 & $70 \cdot 2$ & 80 & $61 \cdot 0$ & 1349 \\
\hline $\begin{array}{l}\text { Consume less } \\
\text { Cholesterol }\end{array}$ & 44.8 & 1147 & $2.71, P=0.44$ & $50 \cdot 0$ & 32 & $39 \cdot 3$ & 66 & $50 \cdot 9$ & 58 & $44 \cdot 8$ & 991 \\
\hline $\begin{array}{l}\text { Consume less } \\
\text { Food groups } \\
\text { Fruits and vegetabl }\end{array}$ & $30 \cdot 4$ & 777 & $0.32, P=0.96$ & $31 \cdot 3$ & 20 & $31 \cdot 0$ & 52 & 37.4 & 43 & $29 \cdot 9$ & 662 \\
\hline $\begin{array}{l}\text { Consume more } \\
\text { Whole grains }\end{array}$ & $66 \cdot 8$ & 1710 & $0.24, P=0.97$ & $73 \cdot 4$ & 47 & 68.5 & 115 & $68 \cdot 7$ & 79 & $66 \cdot 4$ & 1469 \\
\hline $\begin{array}{l}\text { Consume more } \\
\text { Dairy products }\end{array}$ & $44 \cdot 1$ & 1128 & $1.40, P=0.71$ & $50 \cdot 8$ & 33 & $46 \cdot 4$ & 78 & $44 \cdot 3$ & 51 & $43 \cdot 7$ & 967 \\
\hline $\begin{array}{l}\text { Consume less } \\
\text { All meats }\end{array}$ & $25 \cdot 9$ & 663 & $22.06, P<0.001$ & $42 \cdot 2^{a}$ & 27 & $41 \cdot 1^{a}$ & 69 & $38 \cdot 3^{a, b}$ & 44 & $23 \cdot 7^{b}$ & 523 \\
\hline $\begin{array}{l}\text { Consume less } \\
\text { Red meat only }\end{array}$ & $20 \cdot 3$ & 520 & $61.64, P<0.001$ & $42 \cdot 2^{\mathrm{a}}$ & 27 & $37 \cdot 5^{a}$ & 63 & $44 \cdot 7^{a}$ & 51 & $17 \cdot 1^{b}$ & 378 \\
\hline $\begin{array}{l}\text { Consume less } \\
\text { Food attributes } \\
\text { Organic foods }\end{array}$ & $28 \cdot 7$ & 733 & $14.75, P<0.002$ & $43 \cdot 1^{a, b}$ & 28 & $36 \cdot 9^{a, b}$ & 62 & $49 \cdot 1^{a}$ & 56 & $26 \cdot 5^{\mathrm{b}}$ & 587 \\
\hline $\begin{array}{l}\text { Consume more } \\
\text { Locally produced fo }\end{array}$ & $36 \cdot 6$ & 936 & $33.02, P<0.001$ & $63 \cdot 1^{a}$ & 41 & $47 \cdot 6^{a}$ & 80 & $58 \cdot 8^{a}$ & 67 & $33 \cdot 8^{b}$ & 748 \\
\hline $\begin{array}{l}\text { Consume more } \\
\text { Ethically sourced, } \\
\text { sourced or fair tra }\end{array}$ & $\begin{array}{l}42 \cdot 9 \\
\text { oly }\end{array}$ & 1097 & $19.61, P<0.001$ & $68 \cdot 8^{a}$ & 44 & $52 \cdot 4^{a, b}$ & 88 & $62 \cdot 3^{a}$ & 71 & $40 \cdot 4^{b}$ & 894 \\
\hline $\begin{array}{l}\text { Consume more } \\
\text { Gluten }\end{array}$ & $29 \cdot 9$ & 764 & 63.06, $P<0.001$ & $62 \cdot 5^{\mathrm{a}}$ & 40 & $46 \cdot 4^{a}$ & 78 & $54 \cdot 4^{\mathrm{a}}$ & 62 & $26 \cdot 4^{b}$ & 584 \\
\hline $\begin{array}{l}\text { Consume less } \\
\text { Aspartame }\end{array}$ & $18 \cdot 0$ & 462 & $8.95, P=0.03$ & 37.5 & 24 & $17 \cdot 9$ & 30 & $25 \cdot 4$ & 29 & $17 \cdot 1$ & 379 \\
\hline $\begin{array}{l}\text { Consume less } \\
\text { Other low-calorie s }\end{array}$ & $\begin{array}{l}30 \cdot 6 \\
\text { rs }\end{array}$ & 782 & $2.22, P=0.53$ & $40 \cdot 6$ & 26 & 31.5 & 53 & $31 \cdot 6$ & 36 & $30 \cdot 2$ & 667 \\
\hline $\begin{array}{l}\text { Consume less } \\
\text { Processed foods }\end{array}$ & 28.7 & 735 & $3.67, P=0.30$ & $40 \cdot 6$ & 26 & $26 \cdot 8$ & 45 & $35 \cdot 1$ & 40 & $28 \cdot 2$ & 623 \\
\hline $\begin{array}{l}\text { Consume less } \\
\text { Genetically modifie }\end{array}$ & $\begin{array}{l}54 \cdot 7 \\
\text { sms }\end{array}$ & 1399 & $1.64, P=0.65$ & $60 \cdot 9$ & 39 & $56 \cdot 5$ & 95 & $62 \cdot 3$ & 71 & $54 \cdot 0$ & 1194 \\
\hline Consume less & 28.9 & 740 & $14.03, P=0.003$ & $50 \cdot 0^{a}$ & 32 & $36 \cdot 3^{a, b}$ & 61 & $41 \cdot 2^{a, b}$ & 47 & $27 \cdot 1^{b}$ & 599 \\
\hline
\end{tabular}

a,b Values within a row with unlike superscript letters were significantly different $(P<0.01)$.

*Sample sizes (total and by type of dietary practice) are shown as weighted values.

$+\chi^{2}$ and $P$ value for the self-reported dietary practice (vegan, vegetarian, pescatarian or none of the above) variable in the logistic regression for each eating effort outcome variable, adjusted for city of recruitment, age, sex, race/ethnicity, BMI, highest level of education completed, perceived income adequacy, health literacy, self-reported nutrition knowledge, frequency of Nutrition Facts table use and survey completion on a mobile browser.

results suggest that a considerable portion of this sample of youth and young adults in major Canadian cities were making efforts to reduce their consumption of animalbased foods.
Vegetarian diets are typically adopted for reasons related to health, animal welfare, environmental sustainability, food cost, and religion or culture ${ }^{(24,25)}$. Although the Canada Food Study survey did not assess respondents' 
personal reasons for limiting animal product consumption, some of our results are suggestive of potential motivations. For example, frequent NFt use was strongly correlated with following a vegan or vegetarian diet. This finding is consistent with those of other studies ${ }^{(23,26,27)}$ which suggest potential health-related motives for limiting animal product consumption and that people with these diets may be more likely to be attuned to nutrition. Vegans and vegetarians may also consult the NFt when selecting foods to help ensure adequate intakes of certain nutrients that are commonly sourced from animal products (e.g. protein, calcium, iron).

The current study also found that respondents reporting a vegan, vegetarian or pescatarian diet were more likely to be concerned about food attributes that may relate to environmental sustainability, compared with respondents without these vegetarian dietary practices. In particular, a greater proportion of respondents following these diets reported making efforts to consume more organic, locally produced and ethically sourced/ sustainably sourced/fair trade foods, and fewer GMO. Foods that are organic, non-GMO, locally produced and/or ethically sourced/sustainably sourced/fair trade are also commonly perceived to be healthier by the public $^{(28,29)}$, despite no strong evidence of an association between the presence of these food attributes and the nutritional quality of that food ${ }^{(30,31)}$. Research has found that positive attitudes towards organic, local and sustainable foods were associated with greater daily servings of fruits and vegetables, higher intakes of dietary fibre, and lower consumption of added sugars and fat among American young adults, suggesting that preferences for foods with these characteristics may be predictive of a healthier diet ${ }^{(32)}$. These findings provide evidence that behaviours which are (or are perceived to be) markers of a healthy and sustainable diet often co-occur among young adults. It is, however, not possible to conclude that health or environmental concerns motivated the eating practices reported in the present study, which may have also been influenced by other factors.

Vegetarian diets were more prevalent among some ethnicities than others. South Asian respondents were the most likely to follow this dietary practice. This finding is not unexpected as many South Asian faiths and cultures are known for customarily practising vegetarian diets ${ }^{(33,34)}$. Previous studies have also shown vegetarian and vegan diets to be associated with a lower BMI and lower rates of obesity among adults and children ${ }^{(23,35,36)}$. It has therefore been proposed that some people may adopt these diets with the aim of losing or managing weight $^{(27,37)}$. The present study, however, did not find that BMI was associated with having vegetarian dietary practices. Research has also shown that vegetarians and vegans are more likely to report low incomes ${ }^{(22,23,38)}$. The lack of association between perceived income adequacy and vegetarian dietary practices observed in our study indicates that financial constraints were less likely to be a primary reason for consuming fewer animal-based foods among this sample of Canadian youth and young adults in major cities.

Unsurprisingly, our study found that a greater proportion of respondents who reported a vegan, vegetarian or pescatarian diet also reported efforts to reduce their overall meat and/or dairy consumption, compared with respondents without these vegetarian dietary practices. Efforts to consume less meat (all types) were significantly more common among respondents with reported vegan, vegetarian or pescatarian diets than those without these dietary practices. Vegans and vegetarians were also more likely to report recent efforts to reduce their dairy consumption. These findings may indicate that some respondents had included dairy and/or meat products in their diets in the year that preceded the survey, and had perhaps only recently adopted these vegetarian dietary practices. Alternatively, some respondents may have reported an aspired dietary practice - rather than one that they had already adopted - which may explain why many respondents with self-reported vegetarian dietary practices also reported recent efforts to consume less meat and/or dairy. While efforts to consume less red meat were not significantly more prevalent among vegans and vegetarians (than among respondents without these dietary practices), some vegans and vegetarians may have reported no recent efforts to limit their intake of red meat if it had already been excluded from their diet for more than 1 year prior to the survey. These observations highlight some limitations to the scope of the survey questions in terms of assessing vegetarian dietary practices and other eating practices. Respondents were not asked to state how long they had been adhering to the reported vegetarian dietary practice. Additionally, the survey did not include an option for respondents to indicate if they were already excluding certain foods (including some or all animal products) from their diets prior to the past year and therefore may not have been making any recent efforts to further alter their consumption of these foods.

The majority of Canadian youth and young adults in this sample reported making efforts to increase or reduce their consumption of a variety of nutrients, food groups and foods with particular attributes. Reductions in sugar intake and increases in protein consumption were commonly targeted eating practices, which may reflect the attention that these nutrients have recently been receiving from public health authorities and the media( ${ }^{(39-41)}$. In addition, approximately two-thirds of the sample reported making an effort to consume more fruits and vegetables, which is encouraging given that as of 2015 , nearly $70 \%$ of Canadians (aged 12+ years) failed to consume fruits and vegetables at least five times daily ${ }^{(1)}$. In terms of food attributes, the results showed that more than half of the overall sample reported having made an effort to reduce their consumption of processed foods. This result is 
also promising as, on average, approximately half of the daily energy intake of Canadian adults is derived from ultra-processed foods, such as pre-prepared meals, snack foods and sugar-sweetened beverages ${ }^{(6)}$. These reported eating practices collectively align with Canada's recently released Food Guide, which recommends regular consumption of vegetables, fruit, whole grains and protein foods, with plant-based protein foods being consumed more often ${ }^{(5)}$. Canada's Food Guide also encourages lower intakes of processed and pre-prepared foods as they can contribute excess sodium, free sugars and saturated fats ${ }^{(5)}$. The eating practices reported by most young Canadians in our sample are also consistent with global targets recently established by the EAT-Lancet Commission, which include shifting towards greater consumption of fruits and vegetables, nuts and legumes, and reducing intakes of highly processed foods, added sugars, red meat and other animal-source foods ${ }^{(15)}$. Future work will help to assess whether or not these efforts translate into meaningful dietary and environmental outcomes.

To our knowledge, the present study is among the first to assess eating practices among Canadian youth and young adults, including following dietary practices that limit their consumption of animal products. Strengths of the study included a large sample size and analysis that adjusted for sociodemographic characteristics and health behaviours likely to be associated with reporting vegetarian dietary practices. Despite these strengths, this work is not without limitations. First, the Canada Food Study did not recruit participants using probability-based sampling and recruited participants from five major Canadian cities only, thereby limiting the generalizability of our results. For example, youth and young adults living in rural Canada may have been under-represented in our sample, whose diet quality and eating practices may differ from those of young Canadians residing in urban areas. Compared with national estimates, the present study participants were somewhat more likely to report food insecurity and to be students; however, the prevalences of overweight and obesity in our sample were similar to national estimates ${ }^{(18)}$. In addition, because the Canada Food Study survey did not provide definitions of the different vegetarian dietary practices examined in the current study, some respondents may have inadvertently misreported their diet type; for example, if a respondent included seafood (but not meat) in their diet and identified as 'vegetarian' rather than 'pescatarian'. Responses to the survey questions may have also been affected by a social desirability reporting bias, particularly in answering questions about their efforts to consume more or less of particular nutrients, food groups or food attributes that are generally perceived by the public as either healthy or less healthy; however, the use of an online survey may decrease reporting bias for health-sensitive issues compared with in-person interviews. Similarly, the accuracy of respondents' answers to these types of survey questions may have been limited by poor recall or confusing an intent with an action.

\section{Conclusions}

Overall, nearly $14 \%$ of Canadian youth and young adults in this sample reported dietary practices that limit their consumption of some or all forms of animal products, and many also reported other eating practices with potential positive implications for both the nutritional quality and environmental sustainability of their dietary patterns.

\section{Acknowledgements}

Financial support: This project has been made possible through funding from the Public Health Agency of Canada (PHAC). Additional funding for this project has been provided by a PHAC-Canadian Institutes of Health Research (CIHR) Chair in Applied Public Health, which supports D.H., staff and students at the University of Waterloo. L.Va. has received support as a CIHR Banting Postdoctoral Fellow. L.Ve. is supported by an Ontario Graduate Scholarship. None of these funding organizations had any role in the design, analysis or writing of this article. Conflict of interest: L.Ve. and L.Va. have conducted research examining food company policies and through this work have engaged with food industry stakeholders; the authors do not accept funding from the food industry. Authorship: D.H. designed the overall study and secured the funding. D.H. and C.M.W. coordinated data collection. C.M.W. prepared the data set. L.Ve., L.Va., V.L.R. and D.H. designed the analyses. L.Ve. conducted the analyses and drafted the manuscript. All authors critically reviewed the manuscript and approved the final version. Ethics of human subject participation: This study was conducted according to the guidelines laid down in the Declaration of Helsinki and all procedures involving research study participants were approved by a University of Waterloo Research Ethics Committee (ORE\# 21631). Written informed consent was obtained from all participants.

\section{References}

1. Public Health Agency of Canada (2017) At-a-glance - The 2017 Canadian Chronic Disease Indicators. https://www. canada.ca/en/public-health/services/reports-publications/ health-promotion-chronic-disease-prevention-canada-researchpolicy-practice/vol-37-no-8-2017/at-a-glance-2017-canadianchronic-disease-indicators.html (accessed February 2019).

2. Statistics Canada (2017) Fruit and Vegetable Consumption, 2015. Health Facts Sheets, 82-625-X. http://www.statcan. gc.ca/pub/82-625-x/2017001/article/14764-eng.htm (accessed February 2019). 
3. Health Canada (2015) Evidence Review for Dietary Guidance: Summary of Results and Implications for Canada's Food Guide. https://www.canada.ca/en/health-canada/ services/publications/food-nutrition/evidence-review-dietaryguidance-summary-results-implications-canada-food-guide. html (accessed February 2019).

4. Statistics Canada (2015) Protein sources in the Canadian diet, 2015. Infographics, 11-627-M. https://www150.statcan.gc. $\mathrm{ca} / \mathrm{n} 1 / \mathrm{pub} / 11-627-\mathrm{m} / 11-627-\mathrm{m} 2018004-e n g . h t m$ (accessed May 2019).

5. Health Canada (2019) Canada's Dietary Guidelines. SECTION 2 Foods and beverages that undermine healthy eating. https://food-guide.canada.ca/en/guidelines/section-2foods-and-beverages-that-undermine-healthy-eating/ (accessed February 2019).

6. Nardocci M, Leclerc BS, Louzada ML et al. (2019) Consumption of ultra-processed foods and obesity in Canada. Can J Public Health 110, 4-14.

7. Jessri M, Nishi SK \& L'Abbé MR (2015) Assessing the nutritional quality of diets of Canadian adults using the 2014 Health Canada Surveillance Tool tier system. Nutrients 7, 10447-10468.

8. Poobalan AS, Aucott LS, Clarke A et al. (2014) Diet behaviour among young people in transition to adulthood (18-25 year olds): a mixed method study. Health Psychol Behav Med 2, 909-928.

9. Beaglehole R, Bonita R, Horton R et al. (2011) Priority actions for the non-communicable disease crisis. Lancet $\mathbf{3 7 7}$, $1438-1447$.

10. Schermel A, Mendoza J, Henson S et al. (2014) Canadians' perceptions of food, diet, and health - a national survey. PLoS One 9, e86000.

11. Mintel Group Ltd (2017) Two in three Canadians agree eating healthy positively impacts emotional well-being. http:// www.mintel.com/press-centre/food-and-drink/healthy-eatingimpacts-canadians-well-being (accessed February 2019).

12. The Nielsen Company, LLC (2017) Healthy habits make healthy Canadians. https://www.nielsen.com/ca/en/insights/news/ 2017/healthy-habits-make-healthy-canadians.html (accessed February 2019).

13. Dinu M, Abbate R, Gensini GF et al. (2017) Vegetarian, vegan diets and multiple health outcomes: a systematic review with meta-analysis of observational studies. Crit Rev Food Sci Nutr 57, 3640-3649.

14. Appleby PN \& Key TJ (2016) The long-term health of vegetarians and vegans. Proc Nutr Soc 75, 287-293.

15. Willett W, Rockström J, Loken B et al. (2019) Food in the Anthropocene: the EAT-Lancet Commission on healthy diets from sustainable food systems. Lancet 393, 447-492.

16. United Nations Standing Committee on Nutrition (2017) Sustainable Diets for Healthy People and a Healthy Planet. Rome: UNSCN.

17. Orlich MJ, Singh PN, Sabaté J et al. (2013) Vegetarian dietary patterns and mortality in Adventist Health Study 2. JAMA Intern Med 173, 1230-1238.

18. Hammond D, White CM \& Reid JL (2018) Canada Food Study: Technical Report - Wave 1 (2016). http://canadafoodstudy. $\mathrm{ca} /$ studydocs (accessed February 2019).

19. Pfizer (2018) The Newest Vital Sign: A Health Literacy Assessment Tool for Patient Care and Research. https:// www.pfizer.com/health/literacy/public-policy-researchers/ nvs-toolkit (accessed February 2019).

20. Statistics Canada (2019) Table 051-0001 - Estimates of Population, by Age Group and Sex for July 1, Canada, Provinces and Territories, Annual (Persons Unless Otherwise Noted), CANSIM (Database). https://www150. statcan.gc.ca/t1/tbl1/en/tv.action?pid=1710000501 (accessed February 2019).

21. Charlebois S, Somogyi S \& Music J (2018) Plant-based dieting and meat attachment: Protein wars and the changing Canadian consumer (Preliminary Results). https://cdn. dal.ca/content/dam/dalhousie/pdf/management/News/News $\% 20 \% 26 \% 20$ Events/Charlebois\%20Somogyi\%20Music\%20EN \%20Plant-Based\%20Study.pdf (accessed February 2019).

22. Allès B, Baudry J, Méjean C et al. (2017) Comparison of sociodemographic and nutritional characteristics between self-reported vegetarians, vegans, and meat-eaters from the NutriNet-Santé study. Nutrients 9, E1023.

23. Bedford JL \& Barr SI (2005) Diets and selected lifestyle practices of self-defined adult vegetarians from a populationbased sample suggest they are more 'health conscious'. Int $J$ Behav Nutr Phys Act 2, 4.

24. Leitzmann C (2014) Vegetarian nutrition: past, present, future. Am J Clin Nutr 100, Suppl. 1, 496S-502S.

25. Craig WJ, Mangels AR \& American Dietetic Association (2009) Position of the American Dietetic Association: vegetarian diets. J Am Diet Assoc 109, 1266-1282.

26. Hoek AC, Luning PA, Stafleu A et al. (2004) Food-related lifestyle and health attitudes of Dutch vegetarians, nonvegetarian consumers of meat substitutes, and meat consumers. Appetite 42, 265-272.

27. Heiss S, Coffino JA \& Hormes JM (2017) Eating and health behaviors in vegans compared to omnivores: dispelling common myths. Appetite 118, 129-135.

28. Robinson-O'Brien R, Larson N, Neumark-Sztainer D et al. (2009) Characteristics and dietary patterns of adolescents who value eating locally grown, organic, nongenetically engineered, and nonprocessed food. J Nutr Educ Behav 41, 11-18.

29. Hughner RS, McDonagh P, Prothero A et al. (2007) Who are organic food consumers? A compilation and review of why people purchase organic food. J Consum Behav $\mathbf{6}$, 94-110.

30. Smith-Spangler C, Brandeau ML, Hunter GE et al. (2012) Are organic foods safer or healthier than conventional alternatives?: a systematic review. Ann Intern Med 157, 348-366.

31. Edwards-Jones G (2010) Does eating local food reduce the environmental impact of food production and enhance consumer health? Proc Nutr Soc 69, 582-591.

32. Pelletier JE, Laska MN, Neumark-Sztainer D et al. (2013) Positive attitudes toward organic, local, and sustainable foods are associated with higher dietary quality among young adults. I Acad Nutr Diet 113, 127-132.

33. Caplan P (2008) Crossing the veg/non-veg divide: commensality and sociality among the middle classes in Madras/ Chennai. S Asia 31, 118-142.

34. Jin Y, Kanaya AM, Kandula NR et al. (2018) Vegetarian diets are associated with selected cardiometabolic risk factors among middle-older aged South Asians in the United States. J Nutr 148, 1954-1960.

35. Colombet Z, Allès B, Si Hassen W et al. (2019) Individual characteristics associated with changes in the contribution of plant foods to dietary intake in a French prospective cohort. Eur J Nutr 58, 1991-2002.

36. Sabaté J \& Wien M (2010) Vegetarian diets and childhood obesity prevention. Am J Clin Nutr 91, issue 5, 1525S-1529S.

37. Dyett PA, Sabaté J, Haddad E et al. (2013) Vegan lifestyle behaviors: an exploration of congruence with healthrelated beliefs and assessed health indices. Appetite $\mathbf{6 7}$, 119-124. 
38. Neff RA, Edwards D, Palmer A et al. (2018) Reducing meat consumption in the USA: a nationally representative survey of attitudes and behaviours. Public Health Nutr $\mathbf{2 1}$, 1835-1844.

39. Elliott-Green A, Hyseni L, Lloyd-Williams F et al. (2016) Sugar-sweetened beverages coverage in the British media: an analysis of public health advocacy versus pro-industry messaging. BMJ Open 6, e011295.
40. World Health Organization (2015) WHO calls on countries to reduce sugar intake among adults and children. https://www. who.int/mediacentre/news/releases/2015/sugar-guideline/ en/ (accessed February 2019).

41. Mintel Group Ltd (2014) Protein fever. High protein is proving to be more than just a fad - but will it change the way we eat? http://tolsonedtc620.weebly.com/uploads/4/0/7/1/40716697/ protein-whitepaper-mintel.pdf (accessed February 2019). 